\title{
NEGOSIASI ANTARA TRADISI DAN MODERNITAS DI PESANTREN AS'ADIYAH SENGKANG SULAWESI SELATAN
}

\section{Muhammad Takbir Malliongi}

\author{
Mahasiswa Pasca Sarjana Fakultas Filsafat \\ Universitas Gadjah Mada \\ Email:abhimalliongi@gmail.com
}

\begin{abstract}
This research discusses the space of negotiation between tradition and modernity at the As'adiyah pesantren Sengkang Wajo in South Sulawesi. The aim is to find the horizon of the As'adiyah-ness in the context of hegemonic modernizing pesantren. The data collection was carried out by using the qualitative method, that is participant observation and interview. The data was analyzed using post-colonial theory. The result is that the modernization of pesantren is the hegemonic to support the development program of the New Order government at the time. Because of it, As'adiyah have to accommodate modernity. However, in the its process determine negotiations between the pesantren tradition and modernity, that is a third place showing a modern organization and integrated curriculum.
\end{abstract}

Keywords: As'adyah Pesantren, Negotiation, the Third Place, Tradition and modernity

\begin{abstract}
Abstrak
Penelitian ini membahas tentang ruang negosiasi antara tradisi dan modernitas di pesantren As'adiyang Sengkang Wajo Sulawesi Selatan. Tujuannya adalah untuk menemukan horizon ke-As'diyah-an di tengah arus modernisasi pesantren yang hegemonik. Pengumpulan data dilakukan dengan metode kualitatif, yaitu; participant observation dan wawancara Data tersebut selanjutnya diolah dan dianalisis dengan menggunakan kerangka teori pascakolonial. Sebagai hasilnya, tampak bahwa modernisasi pesantren yang berlangsung hegemonik bertujuan untuk mendukung program pembangunan pemerintah Orde Baru. Kenyataan ini pada gilirannya mendorong As'adiyah mengakomodir modernitas. Namun demikian, dalam proses akomodasi As'adiyah tidaklah pasif, akan tetapi berlangsung negoisasi antara tradisi kepesantrenan dan modernitas. Proses ini selanjutnya melahirkan ruang ketiga dalam bentuk organisasi modern dan kurikulum terpadu.
\end{abstract}

Kata Kunci: Pesantren As'diyah, Negoisasi, Ruang Ketiga, Tradisi dan Modernitas. 


\section{A. PENDAHULUAN}

Pesantren As'adiyah didirikan oleh (almarhum) Anregurutta Kiai Haji Muhammad As'ad pada tahun 1930 di Sengkang Wajo Sulawesi Selatan. Pada mulanya pesantren ini bernama Madrasah Arabiyah Islamiyah sebelum berganti nama menjadi As'adiyah. Nama ini diambil dari nama pendirinya setelah wafatnya pada tahun 1953. Sejak berdirinya 88 tahun silam, As'adiyah telah memberikan pengaruh signifikan terhadap perubahan wajah Islam di jazirah Sulawesi, dan bahkan menjadi rule model dan embrio berdirinya ratusan pesantren di kawasan ini.

Hingga saat ini, As'adiyah pernah diasuh oleh sederet ulama besar, antara lain; Anregurutta H. Muhammad As'ad (1930-1953), Anregurutta H. Daud Ismail (1953-1961), Anregurutta H. Yunus Martan (1961-1986), Anregurutta H. Hamzah Badawi (plt. 1986-1988), Anregurutta H. Abdul Malik bin Muhammad (1988-2000), Prof. Dr. Abdul Rahman Musa (plt. 2000-2002), Anregurutta Rafi Yunus Martan (2002-2018), dan Anregurutta H. Sagena (2018-sekarang).

Pada usianya yang tidak lagi dapat disebut muda, pesantren As'adiyah telah berhasil melewati gelombang zaman; mulai sejak era penjajahan Belanda, Jepang, era kemerdekaan, dan hingga kini. Berbeda dengan beberapa lembaga pesantren lainnya yang justru 'gulung tikar', atau oleh Azumardi Azra dikatakan lenyap akibat tergusur oleh ekspansi sistem pendidikan umum - untuk tidak menyebut sebagai sistem pendidikan "sekular" - atau mengalami transformasi menjadi lembaga

pendidikan umum. ${ }^{1}$ Salah satu alasannya karena As'adiyah mampu bernegoisasi dengan konteks zamannya, termasuk pengetahuan umum. Namun demikian, pesantren ini bukan berarti tidak sentuh sama sekali oleh ekspansi tersebut.

Jika diperhatikan secara terang, kuatnya ekpansi pengetahuan umum ini disebabkan oleh usaha pemerintah untuk memodernisasi pesantren. Ini tampak pada Keputusan Presiden (Keppres) Nomor 34 Tahun 1972 dan Instruksi Presiden (Inpres) Nomor 15 tahun 1974 yang mengatur madrasah di bawah pengelolaan Menteri Pendidikan dan Kebudayaan (Mendikbud) yang sebelumnya sepenuhnya dikelola oleh Kementerian Agama. Tidak berhenti di situ, ini selanjutnya dikuatkan lagi melalui Surat Keputusan Bersama (SKB) 3 Menteri Nomor 6 tahun 1975 dan Nomor 037/U/1975 antara lain Menteri Agama, Menteri Pendidikan dan Menteri Dalam Negeri, tentang Peningkatan Mutu Pendidikan pada Madrasah. 
Pada satu sisi, kebijakan modernisasi ini mendapat respon positif dari kalangan pesantren, namun pada sisi lain tidak sedikitnya juga yang menolaknya. As'diyah adalah satu satu pesantren yang merespon secara positif, dan sebagai konsekuwensinya As'adiyah harus mengaptasi diri sesuai dengan apa yang diinginkan pemerintah. Akibatnya, terjadi perubahan sistemik dalam tubuh As'adiyah ketika itu, termasuk kurikulumnya. Seperti dalam proses belajar-mengajar misalnya, As'adiyah yang mulanya menggunakan kitab rujukannya sendiri serta menggunakan bahasa arab sebagai pengantar, pada akhirnya menggunakan bukubuku rujukan yang ditentukan oleh pemerintah serta menjadikan bahasa Indonesia sebagai bahasa pengantar pembelajaran. Berbeda misalnya dengan pesantren AlSalafiah Mlangi Yogyakarta yang resisten, justru tetap mempertahankan sistem pengajarannya seperti sediakala tanpa acuan pemerintah sama sekali. ${ }^{2}$ Pesantren ini cenderung menutup atau mengasingkan diri dari lingkungan luar. Mereka juga enggan bekerjasama dengan pemerintah, dan bahkan melarang santrinya mengakses media-media global baik berupa televisi maupun internet.

Namun demikian, modernisasi pesantren tentu bukan tanpa masalah. Alihalih membawa perubahan positif seperti diharapkan pemerintah, justru mencabut pesantren dari akarnya. Meskipun kebijakan ini pesantren mendapat status yang sama dengan sekolah umum termasuk kesempatan melanjutkan pendidikan ke jenjang yang lebih tinggi, namun pada sisi lain nilai-nilai kepesantrenan sedikit demi sedikit terkikis. Seperti kecakapan terhadap pengetahuan agama (Islam) dan menjadi moral of force (kekuatan moral) masyarakat. Hal ini diakui Siti Salmia Dahlan dalam disertasi doktoralnya, bahwa terjadi penurunan kualitas output As'adiyah, pasca meninggalnya Anregurutta $\mathrm{As}^{\mathbf{a d}^{3}}$ - masa ini bertepatan dengan awal mula perubahan kurikulum di As'adiyah hingga puncaknya pada tahun 1970-an melalui kebijakan pemerintah di atas. Bahkan, perubahan ini berimplikasi pada perubahan cara pandang komunitas pesantren dari visible-komunalistik menjadi pragmatikindidualistik.

Apabila ditelaah lebih jauh lagi, usaha pemerintah untuk memodernisasi pesantren tidak lepas dari dua hal, yaitu; globalisasi dan ideologi pembangunanisme. Keduanya merupakan wajah lain dari kapitalisme global yang bekerja atas nama moderni(isme)tas. Dalam konteks global misalnya, terdapat kepercayaan bahwa dunia merupakan entitas yang homogen. Kepercayaan ini pada gilirannya 
menghilangkan batas-batas teriorial negara dan benua, dan selanjutnya menjadi celah serta legitimasi berlangsungnya pemberadaban atau (new)kolonialisasi. Kepercayaan ini juga berimplikasi pada cara pandang yang bipolar dan hirarkis; tradional-modern, periferial-metropolis, mitos-ilmiah, rasional-irrasional, dan lain-lain. Terlebih lagi, kepercayaan ini diklaim secara sepihak dari satu masyarakat tertentu; Eropa dan Amerika. Seperti diterangkan oleh Walter D. Mignolo bahwa, In that view of Western civilization may be a dreem: the dreem of actors and institutions that managed and built the modern/colonial word in the name of the universality of the Western values. ${ }^{4}$

Pada konteks kedua, pesantren sebagai salah satu institusi agama, merupakan bagian yang tidak terpisah dari desain dalam pembangunan nasional. Seperti dikemukakan oleh Weber bahwa intitusi agama harus mengambil peran aktif dalam pembangunan seperti institusi lainnya politik dan kebudayaan. Perlu di sini bahwa kerangka ini merupakan bangunan apriorik dari modernisme. Ini berangkat dari satu gagasan umum bahwa keterbelakangan suatu negara disebabkan oleh dirinya sendiri (internal), dan bukan dari luar (eksternal), sehingga diperlukan partisipasi dari berbagai institusi di dalamnya.

Gagasan modernisasi ini menjadi hegemonik dan menguasai alam pikiran masyarakat pesantren di era Orde Baru, dan bahkan berlangsung dalam interval waktu lama. Namun penting dicatat, pesantren As'adiyah bukanlah entitas kultural yang pasif. Membuka diri bukan berarti pasif, taken for granted. Bagi peneliti, karakter dasar kebudayaan, termasuk kebudayaan pesantren, adalah cair dan hibrid, seperti diterangkan oleh Homi K. Bhaba, all culture is characterized by a mixedness - kebudayaan merupakan sebuah proses, sosoknya bersifat sementara, cair, dan tanpa batas-batas yang jelas." ${ }^{, 5}$ Berangkat dari kenyataan inilah, peneliti bermaksud untuk melihat ruang kecairan (ruang ketiga) tersebut, atau dengan kata lain ruang negosiasi antara kedua belah pihak; yang mendominasi dan yang didomonasi, dalam paper ini.

\section{B. METODE PENELITIAN}

Penelitian ini merupakan penelitian lapangan (field research) dengan metode kualitatif (qualitative method). Penelitian ini dilakukan selama dua bulan antara bulan februari hingga bulan april 2016 di pesantren As'adiyah di dua lokasi berbeda yakni; di 
Sengkang (Pusat) dan Macanang Kecamatan Majeuleng (Madrasah Aliah Putera), Kabupaten Wajo Provinsi Sulawesi Selatan. Dari lokasi penelitian ini, peneliti menghimpun berbagai data dan selanjutnya diinventaris menjadi dua jenis data; data primer dan data sekunder. Data primer adalah data yang diperoleh melalui wawancara mendalam, pengamatan terlibat, dokumentasi, serta dokumen-dokumen penting As'adiyah, sedangkan data sekunder adalah data yang diperoleh melalui penelusuran literatur, baik berupa buku maupun penelitian sebelumnya tentang pesantren ini.

Dari data tersebut, selanjutnya dianalisis menggunakan kerangka teori pascakolonial. Tentu saja peneliti membatasi teori pasca-kolonial yang digunakan sebagai analisis mengingat kebutuhan dan kesesuaian objek material penelitian. Di antara yang peneliti gunakan adalah: 1) hegemoni, yakni untuk melihat dominasi modernism, baik oleh Negara maupun global (Amerika dan Eropa); 2) mimikri dan resistensi, yakni untuk melihat bentukbentuk peniruan dan resistensi pesantren sekaligus; 3) hibriditas, yakni untuk melihat ruang ketiga dari hasil negoisasi tradisi pesantren dan modernitas.

\section{PEMBAHASAN}

\section{Melacak Ide Modernisasi Pesantren}

Gagasan modernisasi pendidikan Islam di Indonesia pada dasarnya telah ada sejak era KH. Ahmad Dahlan, founder ormas Muhammadiyah, yang mulai membangun sekolah dengan mengadopsi sistem pendidikan Belanda. Di As'adiyah pun sejak berdinya juga telah menggunakan sistem pendidikan berjengan seperti layaknya sekolah (modern) kolonial kala itu. Namun, istilah ini baru menjadi perbincangan akademis dan berlangsung secara hegemonik pada sekitar 1970-an hingga tahun 1990-an. Di antara tokoh-tokoh yang gencar membicaran hal ini adalah Mukti Ali, Nurcholish Madjid, Azumardi Azra dan Abdurahman Wahid (Gusdur). Mereka pada umumnya, kecuali Gusdur, merupakan intelektual muslim yang pernah pengenyam pendidikan di Amerika Serikat dan Eropa.

Azumardi Azra misalnya secara khusus membahas topik ini dalam bukunya, Pendikan Islam: Tradisi dan Modernisasi Menuju Melinium Baru. Menurutnya,

Kerangka dasar yang berada dibalik "modernisme" Islam secara

keseluruhan adalah bahwa "moderenisasi" pemikiran dan

kelembangaan Islam merupakan prasyarat bagi kebangkitan kaum

muslim di era Moderen. Karena itu, pemikiran dan kelembangaan Islam

- termasuk pendidikan - haruslah dimoderenisasi, sederhanya 
diperbaharui sesuai dengan kerangka "moderenitas": mempertahankan pemikiran kelembagaan Islam "tradisional" hanya akan memperpanjang nestapa ketidakberdayaan kaum muslim dalam berhadapan dengan kemajuan dunia modern. ${ }^{6}$

Azra nampaknya melihat bahwa hanya dengan memodernisasi, pendidikan Islam dapat maju dan berkembang. Moderenisasi adalah keniscayaan, dan tanpa itu pendidikan Islam akan ketinggalan zaman. Tolok ukurnya adalah sekolah umum, atau oleh Mukti Ali, diberikan standar sejauhmana memberikan kontribusi terhadap pembangun nasional. Seperti yang ditegaskan bahwa,

dalam situasi sekarang ini, kriterium untuk mengukur baik dan kurang baiknya pendidikan dan pengajaran, ialah sejauh mana lembaga pendidikan itu dapat menunjang pembangunan.Untuk mengetahui ukuran ini perlu mempelajari rencana dan sasaran strategis pembangunan nasional. ${ }^{7}$

Hal ini seirama dengan pandangan Azra, ketika mengatakan bahwa, moderenisasi - yang di Indonesia lebih dikenal dengan istilah "pembangunan" (development) - adalah proses multi dimensional yang kompleks. Pada satu segi pendidikan dipandang sebagai suatu variabel moderenisasi. ${ }^{8}$ Ini bertujuan sebagai usaha sadar yang digunakan sebagai instrumen untuk perubahan dalam sistem politik dan ekonomi. ${ }^{9}$ Lebih lanjut dijelaskan bahwa, sesuai dengan ideologi developmentalism pemerintah Orde Baru, pembaruan pesantren dalam masa ini mengarah pada pengembangan pandangan dunia dan substansi pendidikan pesantren agar lebih responsif terhadap tantangan zaman. Dalam konteks ini, substansi ilmu kalam yang diajarkan di pesantren diharapkan bukan lagi teologi Asy'ariyah atau Jabariyah, tetapi teologi yang mendorong bagi tumbuhnya prakarsa, usaha etos kerja. $^{10}$

Dengan kata lain, upaya modernisasi pesantren adalah merupakan bagian dari pembangunanisme, sedangkan pembangunanisme tidak lain berperan sebagai instrumen negara dalam usaha menyuburkan kapitalisme global. Oleh sebab itu, tak kala modernisasi menjadi wacana akademis, ia sangat hegemonik mempengaruhi alam pikiran masyarakat pesantren hingga pada alam bawah sadarnya. Seperti diterangkan oleh Biju Kumar, dalam esainya, Postcolonial State, bahwa sedari awal, 
the Marxists interpret the state as an instrument of class domination and an executive committe for managing the affair of the bourgeoisie [...] For the Marxists the postcolonial state was the principal agent for the development of capitalisme in the postcolonial era. ${ }^{11}$

Intitusi pemerintah adalah mesin kekuasaan yang paling efektif memproduksi wacana developmentalismen serta melestarikannya hingga mendapatkan pengaruh hingga dukungan dan persetujuan dari masyarakat umum. Ini bekerja dalam struktur pengetahuan dan berlangsung hingga taraf hegemenik. Laurelyn Whitt menegaskan bahwa,

In the letter part of the twentieth century, began to document the "issues of cultural and economic domination involved in persuit of natural knowledge. The rule of law, they argued, was identified with with the scientific method and become, for the West, a vital means of extending empire. ${ }^{12}$

Seturut dengan itu, Ashis Nandy, juga mengemukakan bahwa penaklukan oleh Eropa dapat dibagi menjadi dua tahap: pertama, penguasaan teritori; dan kedua penaklukan pikiran. Namun, sejak berakhirnya perang dunia kedua, penguasaan teritori tidak lagi memungkinkan, maka langkah kedualah yang digunakan dengan mendakwah ide-ide pencerahannya, seperti; liberalisme, dan modernism.

Berangkat dari gagasan inilah, selanjutnya diciptakan formasi sosial yang mendukung dominasinya. Sebagaimana dijelaskan oleh Mansour Fakih, ${ }^{13}$ bahwa atas kerangka tersebutlah, terdorong adanya perekonomian yang terbuka dan meminimalisir peran negara. Adapun negara hanya sebagai institusi yang mendukung praktik-praktik ekonomi liberal, seperti dukungan negara terhadap pada sistem ekonomi liberal disebut sistem Bretton Woods berikut cara pengelolaannya disebut Marshall Plan.

Lebih lanjut dijelaskan Fakih ${ }^{14}$ tentang lima cara kerja tentang penyebaran gagasan-gagasan pembangunan tersebut; Pertama, menggunakan pengaruh atas berbagai kebijakan ekonomi negara yang dibantunya. Caranya, dengan masuk melalui lembaga seperti USAID; Kedua, melalui pelatihan-pelatihan kepemimpin di negara dunia ketiga. Pengaruhnya ini efektif mengingat pengalaman peran mahasiswa menggulingkan pemerintahan Indonesia pada tahun 1966 dan 1998; Ketiga, dengan menggunakan agama untuk menyebarluaskan gagasan partisipasi 
pembangunan. Ini sangat jelas terlihat pada gagasan-intelektual muslim Indonesia yang pernah mengenyam pendidikan di Amerika dan Eropa seperti misalnya Norcholish Madjid dan Azumardi Azra dengan gagasan modernisasinya; Keempat, adalah dengan menggunakan fungsi pelatihan dan penelitian tenaga universitas yang bekerja di luar negeri dengan USAID; dan kelima, ialah dengan menggunkan pendeta-pendeta Eropa dan Amerika Serikat yang menjalani tugas pelayanan keagamaan di dunia ketiga. Kelima strategi ini sangat soft, hingga kadang tidak disadari oleh peserta yang terlibat.

\section{Modernisasi Pesantren: Antara Mimesis dan Resitensi}

Sebagaimana telah dijelaskan sebelumnya bahwa, modernisasi pesantren di As'adiyah mendapat respon positif. Akibatnya, As'adiyah mengadaptasi diri seperti yang ditetapkan oleh pemerintah. Namun demikian, pola modernisasi ini tidak berjalan parsial, tapi juga berlangsung peniruan secara diam-diam terhadap kebudayaan dominan. Peniruan ini disebut oleh Bhaba sebagai mimikri atau mimesis, yaitu sebuah hasrat untuk meniru yang lain, namun dalam bentuknya tidak persis sama dengan yang ditirunya. Mimikri bagi Bhaba adalah upaya untuk menyingkap keterhubungan subjek atas masa lalunya. Dengan mengutip Lacan, Bhaba menulis,

Mimikri reveal something in so far as distinct form what might be called an itself that behind. The effect of mimicry is camouflage [...] It is not a question of harmonizing with the background, but against a mottled background, of becoming mottled - exactly like the technique of camouflage practiced in human walfere. ${ }^{15}$

Dalam konteks As'adiyah, peneliti menemukan beberapa bentuk peniruan yang dapat dilihat sebagai mimikri. Pertama, tingginya minat belajar santri pada pelajaran bahasa Inggris. Ini dapat dilihat dari antusiasme santri membentuk club bahasa Inggris di sekolah. Bagi mereka, pelajaran ini merupakan ilmu alat selain dari pada bagian dari pelajaran yang masuk dalam ujian nasional. Kendati demikian, santri juga menolak secara tegas Westernisasi (Baratisasi). Dalam wawawancara peneliti, santri mengungkapkan bahwa, "Bahasa Inggris Yes, Westernisasi No". Pandang ini tentu tampak ambigu, karena bagaimana pun bahasa Inggris adalah bagian dari Western - bahasa sebagai bagian dari kebudayaan Barat. 
Kedua, gaya hidup santri yang dapat diidentifikasi cara berpakaiannya. Dalam hemat peneliti, salah satu perubahan gaya hidup santri adalah perubahan kurikulum di pesantren. Identitas kesantrian yang bisanya disimbolkan dengan sarungan, kopia (songkok) dan baju kokoh (gamis) - dalam arti santri tradisional tidak dapat lagi digunakan dalam konteks santri As'adiyah. Karena dalam kenyataanya, bukan hal yang sulit untuk menemukan santri mengenakan kaos oblong, celena pendek dan bahkan jeans di tempat-tempat keramaian. Oleh sebab itu, tidak ada pembeda secara jelas antara santri dengan siswa sekolah umum, kecuali santriwati (puteri) yang tetap dalam frame normatif ala santri.

Bagi santri, cara berpakaian bukanlah subtansi dari kesantrian, yang utama adalah iman. Dari penuturan beberapa santri yang diwawancara oleh peneliti, mereka mengklaim bahwa santri juga harus 'melek' trend, termasuk cara berpakaian, sehingga standarnya pun hanya berdasarkan kepatutan umum. Namun, yang menarik adalah ketika santri mengakui bahwa salah satu alasan tidak melekatkan identitas kesantrian dalam pergaulan sehari-hari adalah tanggung jawab moril daripadanya. Selain itu, diakui pula bahwa ini merupakan strategi untuk menghindari predikatpredikat pejoratif terhadap dirinya, seperti, kolot dan "tidak gaul”. Kendati demikian, mereka juga pada dasarnya tidak ingin kehilangan identitas kesantrian pada sisi yang lain.

Terkait dua hal ini, Anthony Bagues dalam esainya, Imagination, Politics, and utopia: Conforting the Present, menjelaskan bahwa ini bukan semata-mata tentang objek manusia atau tentang apa yang tampak pada manusia secara kasat mata, akan tetapi juga tentang studi kedirian dalam empat bagian yang saling terhubung. Ia menulis,

The first mode is the study of the body, the corporeal structure of our selves; the second is a relational, that is, how the self exist in relation to social, cultural, and economic matters; the third is about the individual self is distinctive; and the four is the appearance of the self focuses on our capacities to tell our stories. ${ }^{16}$

Baginya, perlu dipahami bahwa kenyataan hari ini tidak lepas dari konstruksi sosial politik. Oleh sebab itu, dalam konteks As'adiyah sebagaimana dijelaskan di atas pun tidak dapat dipisahkan dari empat aspek tersebut, termasuk sebagai kenyataan sejarah di masa lalu. 


\section{Negoisasi dan Ruang Ketiga}

As'adiyah meskipun pada dasarnya menerima modernisasi, namun tidak serta mentra dapat dikatakan sebagai pesantren modern - berdasarkan definisi pesantren modern -, dan sebaliknya, juga bukan pesantren salafiah yang konservatif. Karena seperti yang tampak, pesantren ini memang mengakomodir moderenisasi, namun pada bagian tertentu juga menolaknya. Sikapnya yang lentur tersebut pada gilirannya menjadikan As'adiyah sebagai entitas yang unik, atau dalam istilah Gusdur sebagai subkultur. Seperti yang diterangkannya bahwa pesantren sebagai subkultur, memiliki pola hidup menyimpang dari pola kehidupan masyarakat; terdapat sejumlah perjuangan yang menjadi tulang punggung pesantren; berlangsungnya proses pembentukan tata nilai tersendiri dalam pesantren; lengkap dengan simbol-simbolnya; adanya daya tarik keluar, sehingga memungkinkan masyarakat sekitar menganggap pesantren sebagai alternatif ideal bagi sikap hidup yang ada di masyarakat itu sendiri; dan berkembangnya suatu proses pengaruhmempengaruhi dengan masyarakat diluarnya, yang akan berkulminasi pada pembentukan nilai-nilai baru yang secara universal diterima oleh kedua belah pihak. ${ }^{17}$

Apabila diperhatikan secara lebih dekat, paling tidak ada dua sifat yang dimiliki As'adiyah sehingga tetap bertahan hingga hari ini, yakni: adjustment (akomodasi) dan rejustment (penyesuaian). Akomodasi misalnya, dapat dilihat dalam dua bentuk, yakni: pertama, sistem pesantren yang dikelola secara modern - secara jelas memuat prinsip demokrasi; dan kedua, berlakunya sistem kurikulum terpadu dimasukannya kurikulum pemerintah pada semuan jenjang pendidikan, mulai dari Ibtida'iyah hingga Aliyah, serta mendapat porsi yang besar; 60 persen.

Perihal sistem organisasi dan kepemimpinan di As'adiyah diputuskan melalui musyawarah-mufakat. Berbeda dengan beberapa pesantren di nusantara yang justru dikelolah oleh keluarga kiai dan kepemimpinannya diturunkan berdasarkan garis keturunan. Oleh sebab itu, pengelolaannya dilakukan secara modern, terstruktur dan sistematik. Dari merekalah selanjutnya didesain agar wajah pesantren tetap relevan dengan zamannya. ${ }^{18}$ 
Adapun akomodasi lainnya adalah dengan lahirnya kurikulum terpadu (kurikulum umum dan agama). Penerapan kurikulum ini selain karena alasan tuntutan pemerintah juga karena keharusan mereka untuk menyesuian diri dengan kebutuhan madrasah (sekolah). Namun, agar tidak kehilangan identitas kepesantrenannya, As'diyah tetap menggunakan kurikulum agama, meski dengan komposisi yang relatif lebih sedikit. Bahkan, beberapa pelajaran agama hanya dimasukkan dalam kurikulum ekstrakurikuler.

Muhammad Hadrawi, kepala MTs II As'adiyah, percaya bahwa implementasi dari kurikulum terpadu sesungguhnya menjadi ciri khas dan keunggulan yang sulit ditemukan di satuan pendidikan di luar As'diyah. ${ }^{19}$ Tidak berhenti di situ, As'adiyah ke depan bahkan diimajinasikan bisa menjadi MTs Model. Ia berharap kedepan sistem madrasah memiliki aktivitas kegiatan belajar mengajar dari jam 7.30 sampai 13.00 semuanya bermuatan pelajaran umum. Adapun pelajaran keagamaan dan pelajaran kepesantren dilakukan setelahnya dan menjadi kegiatan ekstrakurikular madrasah. $^{20}$

Menurut Azumardi Azra, bertahannya pesantren dikarenakan adanya kompromi dengan moderisasi sehingga membuatnya tradisi Islam relevan. Meskipun pada awalnya, pesantren terlihat "rikuh" dan "enggan" menerima moderinisasi; sehingga tercipta kesenjangan antara pesantren dengan dunia luar, namun secara gradual pesantren akhirnya melakukan akomodasi. Langkah ini terbilang tepat guna dalam menghadapi perubahan zaman yang sangat cepat serta berdampak luas. Kendati demikian, semua akomodasi dan penyesuaian itu dilakukan pesantren tanpa mengorbankan esensi dan hal-hal dasar pesantren. ${ }^{21}$

Pada dasarnya, munculnya resistensi pesantren terhadap modernisasi lebih disebabkan oleh konotasi "Barat". Terlebih lagi, sebagian kalangan pesantren memandang moderenisasi adalah bentuk penghalusan dari westernisasi. ${ }^{22}$ Meskipun anggapan ini tidak sepenuhnya salah, namun juga tidak dibenarkan sama sekali. Seperti yang telah dijelaskan sebelumnya, bahwa modernisasi pesantren oleh banyak pihak selalu diasosiasikan sebagai developmentalism. Pada konteks ini, modernisasi merupakan bagian westernisasi. Namun, ketika modernisasi dipandang sebagai kontekstualisasi tentu saja adalah sebuah tuntutan. Karena bagaimanapun, salah tujuan dari pada pendidikan adalah menjawab persoalan-persoalan sosial. 
Alasan lain terjadinya resistensi terhadap modernisasi adalah disebabkan karena ketidakmampuan pesantren mengikuti laju moderenisasi sehingga akhirnya memutuskan untuk menutup diri. Padahal sejatinya pesantren mampu menjawab tantangan tersebut, dan bukan justru menghindarinya. Pesantren yang memilih jalan ini, secara umumnya ditinggalkan oleh santrinya secara perlahan.

Jika melihat sejarah pesantren, sikap resisten ini terasah dan memuncak di era kolonialisasi. Pesantren kala itu menjadi garda terdepan menantang kolonialisasi. Ini terang terlihat pada dalam pemberontakan di pulau Jawa yang di mulai di pesantren. Berbeda misalnya dengan era pra-kolonial, pesantren justru sangat akomodatif dan lentur.

Kemampuan As'adiyah bernegoisasi (adjustment dan rejustment) membawanya tetap eksis hingga saat ini. Bahkan, sebuah kenyataan yang tidak dapat ditolak, bahwa As'adiyah telah berkontribusi secara nyata dalam proses transformasi pembangunan di Indonensi secara umum dan Wajo secara khusus. Ini paling tidak dapat dilihat paling tidak dari dua aspek, yakni sumbangsih dalam pengembangan sumber daya manusia, khususnya berkenaan dengan proses Islamisasi di kawasan ini.

\section{PENUTUP}

Tradisi dan modernitas pada prinsipnya bukan sesuatu yang bertentangan satu sama lain. Ini tampak terlihat di pesantren As'diyah Sengkang Wajo Sulawesi Selatan dimana keduanya bernegoisasi dalam satu ruang yang sama. Meskipun seringkali tampil dominan dan seolah-olah menegasi tradisi, modernitas dan modernisme tidak pernah terterima secara taken for granted, karena ia tidak hadir dalam suatu ruang kosong yang tanpa tradisi. Oleh sebab itu, keberadaannya selalu meniscayakan adanya negosisasi tradisi di tempat ia berada. Jika pun moderinitas bekerja secara hegemonik dan pada gilirannya melahirkan relasi yang tidak setara, maka selanjutnya melahirkan yang berbeda, yakni; mimesis dan resistensi. Namun demikian, perlu diketahui juga bahwa mimesis bukanlah peniruan yang sebagaimana adanya, karena hal tersebut merupakan kamuflase dari sang subjek peniru. 


\section{Endnotes:}

1 Azyumardi Azra, "Pesantren: Kontinuitas dan Perubahan (Pengantar)," in Bilik-Bilik Pesantren: Sebuah Potret Perjalanan, Nourcholish Madjid (Jakarta: Paramadina, 1997), ix.

2 Richana, Respon Pondok Pesantren Tradisional Terhadap Sistem Pendidikan Modern: Studi Pelaksanaan sistem Kredit Semester di Pondok Al-Salafiah Mlangi Yogyakarta (Tesis UIN Sunan Kalijaga Yogyakarta, 2004)

${ }^{3}$ Siti Salmiah Dahlan, Rihlah Ilmiah AGH. Muhammad As'ad Dari Haramain ke Wajo Celebes: Sebuah Perjalanan Religi Untuk Membangun Madrasah Arabiyah Islamiyah di Wajo Sulawesi Selatan (Jakarta: Rabbani Press, 2013), 264.

${ }^{4}$ Walter D. Mignolo, Local Histories/Global Designs: Coloniality, Subaltern Knowledge and Border Thingking (Princeton \& Oxord: Princeton University Press, 2012), x.

${ }^{5}$ Bachtiar Alam, "Globasasi dan Perubahan Budaya," Jurnal Antropologi Indonesia 56, (1998): 7.

6 Azyumardi Azra, Pendidikan Islam: Tradisi dan Modernisasi Menuju Melinium Baru (Jakarta: Logos, 1999), 31.

${ }^{7}$ Azra, Pendidikan Islam, 33.

${ }^{8}$ Azra, Pendidikan Islam, 33.

${ }^{9}$ Azra, Pendidikan Islam, 32.

${ }^{10}$ Azra, "Pesantren," xxi.

${ }^{11}$ Biju Kumar, "Postcolonial State: An Overview," The Indian Journal of Political Science 66, No. 4 (Oct. - Dec., 2005): 937, http://www.jstore.org/stable/41856176.

${ }^{12}$ Laurelyn Whitt, Science, Colonialism, and Indigenous People: The Cultural Politics of Low and Knoledge (Cambrige: Cambrige University Press, 2009), xii.

13 Mansour Fakih, "Pembanguan: Politik Hegemoni (Pengantar)," in Menolak Pembangunanisme, Saiful Arif (Yogyakarta: Pustaka Pelajar, 2000), xviii.

${ }^{14}$ Mansour Fakih, "Pembanguan," xix-xx.

${ }^{15}$ Homi K. Bhaba, The Location of Culture (London \& New York: Routledge, 1994), 85.

${ }^{16}$ Anthony Bagues, Imagination, Politics, and utopia: Conforting the Present, tt., 152.

17 Abdurrahman Wahid, Bunga Rampai Pesantren: Kumpulan Karya Tulis Abdurrahman Wahid (Jakarta: Dharma Bakti, 1399 H), 10.

${ }^{18}$ Djohan Effendi, Pembaruan Tanpa Membongkar Tradisi: Wacana Keagamaan Generasi Muda NU Masa Kepemimpinan Gus Dur (Jakarta: Kompas, 2010), 5.

${ }^{19}$ Mimbar As'adiyah, edisi 1, Rabiul Awal 1437/ Desember 2015, 36.

${ }^{20}$ Wawancara Pribadi dengan Muhammad Hadrawi pada tanggal 15 Maret 2016 di kantor kepala sekolah MTs As'adiyah II di Sengkang.

${ }^{21}$ Azra, "Pesantren," xxv.

${ }^{22}$ Azra, "Pesantren," 89.

\section{DAFTAR PUSTAKA}

Azra, Azyumardi. "Pesantren: Kontinuitas dan Perubahan (Pengantar)." In Bilik-Bilik Pesantren: Sebuah Potret Perjalanan, Nourcholish Madjid, Jakarta: Paramadina, 1997.

Pendidikan Islam: Tradisi dan Modernisasi Menuju Melinium Baru. Jakarta: Logos, 1999.

Bachtiar, Alam. "Globasasi dan Perubahan Budaya." In Jurnal Antropologi Indonesia, 56, (1998). 
Bagues, Anthony. tt. Imagination, Politics, and utopia: Conforting the Present. tp.

Bhaba, Homi K., The Location of Culture. London \& New York: Routledge, 1994.

Dahlan, Siti S., Rihlah Ilmiah AGH. Muhammad As'ad Dari Haramain ke Wajo Celebes: Sebuah Perjalanan Religi Untuk Membangun Madrasah Arabiyah Islamiyah di Wajo Sulawesi Selatan. Jakarta: Rabbani Press, 2013.

Effendi, Djohan. Pembaruan Tanpa Membongkar Tradisi: Wacana Keagamaan Generasi Muda NU Masa Kepemimpinan Gus Dur. Jakarta: Kompas, 2010.

Fakih, Mansour. "Pembanguan: Politik Hegemoni (Pengantar)." In Menolak Pembangunanisme, Saiful Arif, Yogyakarta: Pustaka Pelajar., 2000.

Mignolo, Walter D., Local Histories/Global Designs: Coloniality, Subaltern Knowledge and Border Thingking. Princeton \& Oxord: Princeton University Press., 2012.

Mimbar As'adiyah, 2015. Edisi 1, Rabiul Awal 1437/ Desember.

Richana. Respon Pondok Pesantren Tradisional Terhadap Sistem Pendidikan Modern: Studi Pelaksanaan sistem Kredit Semester di Pondok Al-Salafiah Mlangi Yogyakarta. Tesis UIN Sunan Kalijaga Yogyakarta, 2004.

Kumar, Biju. "Postcolonial State: An Overview." In The Indian Journal of Political Science 66, no. 4 (2005). hppt://www.jstore.org/stable/41856176.

Wahid, Abdurrahman, Bunga Rampai Pesantren: Kumpulan Karya Tulis Abdurrahman Wahid. Jakarta: Dharma Bakti, 1977.

Whitt, Laurelyn. Science, Colonialism, and Indigenous People: The Cultural Politics of Low and Knoledge. Cambrige: Cambrige University Press, 2009. 